\title{
Rottlerin Inhibits ROS Formation and Prevents NF $\kappa$ B Activation in MCF-7 and HT-29 Cells
}

\author{
Emanuela Maioli, ${ }^{1}$ Lucedio Greci, ${ }^{2}$ Karel Soucek, ${ }^{3}$ Martina Hyzdalova, ${ }^{3}$ \\ Alessandra Pecorelli, ${ }^{1}$ Vittoria Fortino, ${ }^{1}$ and Giuseppe Valacchi ${ }^{4,5}$ \\ ${ }^{1}$ Dipartimento di Fisiologia, University of Siena, via Aldo Moro, 7 - 53100 Siena, Italy \\ ${ }^{2}$ Dipartimento ISAC, Sezione Chimica, via Brecce Bianche, Università Politecnica delle Marche, I-60131 Ancona, Italy \\ ${ }^{3}$ Department of Cytokinetics, Institute of Biophysics AS CR, v.v.i., Kralovopolska 135, 61265 Brno, Czech Republic \\ ${ }^{4}$ Dipartimento di Scienze Biomediche, University of Siena, via Aldo Moro, 7 - 53100 Siena, Italy \\ ${ }^{5}$ Department of Food and Nutrition, Kyung Hee University, 130-701 Seoul, South Korea
}

Correspondence should be addressed to Giuseppe Valacchi, valacchi8@unisi.it

Received 20 July 2009; Revised 9 October 2009; Accepted 5 November 2009

Recommended by Stelvio M. Bandiera

Rottlerin, a polyphenol isolated from Mallotus Philippinensis, has been recently used as a selective inhibitor of PKC $\delta$, although it can inhibit many kinases and has several biological effects. Among them, we recently found that Rottlerin inhibits the Nuclear Factor $\kappa \mathrm{B}(\mathrm{NF} \kappa \mathrm{B})$, activated by either phorbol esters or $\mathrm{H}_{2} \mathrm{O}_{2}$. Because of the redox sensitivity of $\mathrm{NF} \kappa \mathrm{B}$ and on the basis of Rottlerin antioxidant property, we hypothesized that Rottlerin could prevent NFKB activation acting as a free radicals scavenger, as other natural polyphenols. The current study confirms the antioxidant property of Rottlerin against the 2,2-diphenyl-1-picrylhydrazyl radical (DPPH) in vitro and against oxidative stress induced by $\mathrm{H}_{2} \mathrm{O}_{2}$ and by menadione in culture cells. We also demonstrate that Rottlerin prevents TNF $\alpha$-dependent NF $\kappa$ B activation in MCF-7 cells and in HT-29 cells transfected with the NF $\kappa$ B-driven plasmid pBIIX-LUC, suggesting that Rottlerin can inhibit $\mathrm{NF} \kappa \mathrm{B}$ via several pathways and in several cell types.

Copyright (c) 2009 Emanuela Maioli et al. This is an open access article distributed under the Creative Commons Attribution License, which permits unrestricted use, distribution, and reproduction in any medium, provided the original work is properly cited.

\section{Introduction}

Rottlerin (also called mallotoxin or kamala) is a pigmented plant product isolated from MallotusPhilippinensis (Figure 1), used in India in ancient times as a remedy for tapeworm [1-3].

Since 1994, Rottlerin has been used as a PKC $\delta$ inhibitor based on in vitro studies that have shown that the IC50 for PKC $\delta$ was $3-6 \mu \mathrm{M}$ compared to $30-100 \mu \mathrm{M}$ for the other PKC isozymes [4], although the selectivity of Rottlerin in inhibiting PKC $\delta$ isoform has been recently questioned [5].

Several phloroglucinol derivatives, which are similar to Rottlerin in structure, have been demonstrated to have antiinflammatory and antiallergic properties $[6,7]$.

Moreover, Rottlerin can target mitochondria, interfering in the respiratory chain as an uncoupler of oxidative phosphorylation [8], and activates the large conductance voltage and $\mathrm{Ca}^{++}$activated $\mathrm{K}^{+}$channel (BK) in human vascular smooth muscle; its use has been patented (patent
$\mathrm{WO} / 2006 / 060196)$ in the therapy of hypertension and related disorders [9].

Our laboratory showed for the first time that Rottlerin can suppress $\mathrm{NF} \kappa \mathrm{B}$ activation induced by either phorbol ester or $\mathrm{H}_{2} \mathrm{O}_{2}$, in MCF-7 cells and in HaCaT keratinocytes, respectively, in a PKC-independent way $[10,11]$. Rottlerin is a pleiotropic inhibitor, able to inhibit the activity of a number of unrelated kinases, such as $\mathrm{AKT} / \mathrm{PKB}$ and calmodulin-dependent kinases (CaMKs) I-III $[12,13]$, two known upstream mediators of the $\mathrm{NF} \kappa \mathrm{B}$ activation process [14-19].

Although the underlying molecular mechanisms have not been yet investigated in details Rottlerin interference in the $\mathrm{NF} \kappa \mathrm{B}$ activation process was likely achieved, in MCF-7 cells, through inhibition of CaMKII, without involvement of the AKT/PKB pathway [10].

The transcription factor $\mathrm{NF} \kappa \mathrm{B}$ consists of p50 and p65 heterodimer, which is retained in the cytoplasm by masking nuclear localization signal (NLS) by the inhibitor $\mathrm{I} \kappa \mathrm{B} \alpha$. 
<smiles>CC(=O)c1c(O)c(C)c(O)c(Cc2c(O)c3c(c(C(=O)/C=C/c4ccccc4)c2O)OC(C)(C)C=C3)c1O</smiles>

Figure 1: Chemical structure of Rottlerin.

Upon activation, $\mathrm{I} \kappa \mathrm{B} \alpha$ kinase (IKK) phosphorylates $\mathrm{I} \kappa \mathrm{B} \alpha$, promotes its ubiquitination and degradation, thus allowing p50-p65 to translocate to the nucleus, bind to its consensus sequence, and induce transcription of genes essential for cell proliferation and survival [20]. Consistently, Rottlerin inhibition of $\mathrm{NF} \kappa \mathrm{B}$ caused downregulation of cyclin D1 and growth arrest in both MCF-7 and in HaCaT cells $[10,11]$.

Because $\mathrm{NF} \kappa \mathrm{B}$ can be activated by a number of signaling molecules [21], we performed further experiments to support the idea that Rottlerin inhibits $\mathrm{NF} \kappa \mathrm{B}$ in different cell types and under different stimuli.

One interesting characteristic of $\mathrm{NF} \kappa \mathrm{B}$ is its extreme sensitivity to cellular redox state [22]. Since many agents activating NFkB are modulated by Reactive Oxygen Species (ROS) or by pro-oxidants, we wondered whether the inhibitory effects of Rottlerin, previously observed by us, could be also due to its antioxidant potential. Rottlerin, indeed, is a 5,7-dihydroxy-2,2-dimethyl-6-(2,4,6-trihydroxy-3-methyl5-acetylbenzyl)-8-cinnamoyl-1,2-chromene and contains five phenolic hydroxyl groups that might likely act as hydrogen donors in the scavenging of free radicals in analogy with other polyphenols with documented antioxidant properties. An unexhaustive list of compounds, structurally related to Rottlerin, with antioxidant activity and $\mathrm{NF} \kappa \mathrm{B}$ inhibitory properties comprises Drummondins [23], Flavonoids [24], Resveratrol [25], Genistein [26, 27], Epigallocatechin-3Gallate [28], and Curcumin [29].

Although it could have been deduced from the Rottlerin structure (known at least since 1994), only recently antioxidant properties of Rottlerin have been started to be described [30].

In the current paper, we demonstrate that Rottlerin has antioxidant properties and that the observed inhibitory effect on $\mathrm{NF} \kappa \mathrm{B}$ might be the result of Rottlerin hydrogen donating ability and free radical scavenger activity, in addition to its biological inhibition of signaling molecules. We also provide evidence that Rottlerin inhibits $\mathrm{NF} \kappa \mathrm{B}$ activation in MCF-7 and HT-29 cells and transcriptional activity in cells transfected with the $\mathrm{NF} \kappa \mathrm{B}$-driven plasmid pBIIX-LUC.

\section{Materials and Methods}

2.1. Materials. Minimum Essential Medium (MEM), fetal bovine serum (FBS), antibiotics, dimethylsulfoxide (DMSO),
Na-Pyruvate and L-glutamine and 1,1-Diphenyl-2-picrylhydrazyl (DPPH), and menadione were purchased from Sigma (Milan, Italy), dihydrorhodamine 123 (DHR-123) from Invitrogen, geneticin (G418 sulfate) from Alexis (San Diego, CA), Rottlerin from Calbiochem (Milan, Italy).

2.2. Cells and Culture Conditions. MCF-7 and TH-29 cells were purchased by Istituto Zooprofilattico Sperimentale della Lombardia e dell'Emilia-Romagna, Brescia, Italy. MCF7 cells were grown in humidified atmosphere (95\% air/ $\left.5 \% \mathrm{CO}_{2}\right)$ at $37^{\circ} \mathrm{C}$ in minimum essential medium (MEM) containing 10\% FBS, Na-Pyruvate ( $1 \mathrm{mM})$, and antibiotics. HT-29 cells were grown in Dulbecco's minimum essential medium (DMEM) with 10\% FBS, glutamine $(2 \mathrm{mM})$, and antibiotics. After reaching subconfluence, cells were incubated in serum-free medium for $24 \mathrm{hr}$ and then subjected to treatments in $2.5 \%$ FBS.

2.3. Cell Treatments. MCF-7 and HT-29 cells, pretreated with or without $20 \mu \mathrm{M}$ Rottlerin for $30 \mathrm{~min}$, were stimulated with $10 \mathrm{ng} / \mathrm{mL} \mathrm{TNF} \alpha$ for $4 \mathrm{hr}$. As to concern the vitamin $\mathrm{E}$ samples, $24 \mathrm{hr}$ preincubation time with $50 \mu \mathrm{M} \alpha$-tocopherol (dissolved in DMSO at the final concentration in the cells of $0.1 \%$ ) was selected on the basis of uptake experiments performed on cells (data not shown).

2.4. Electrophoretic Mobility Shift Assay (EMSA). EMSA assay was performed as previous described by Valacchi et al. 2005 [31]. MCF-7 and HT-29 cells were plated on 100$\mathrm{mm}$ dishes $\left(7.5 \times 10^{5}\right.$ cells/dish $)$ and treated as described above. Cells were washed three times with ice-cold PBS, and dishes placed on dry ice/ethanol. Cells were lysed in

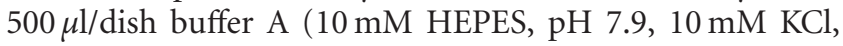
$0.2 \mathrm{mM}$ EDTA, $0.1 \mathrm{mM}$ EGTA, $1 \mathrm{mM}$ DTT, $1 \mathrm{mM}$ PMSF, $1 \mathrm{mM}$ leupeptin) and transferred to microcentrifuge tubes. After incubation for $10 \mathrm{~min}$ on ice, Nonidet P-40 (final concentration $0.02 \%$ ) was added, and suspensions were passed six times through a $26.5 \mathrm{G}$ needle to optimize cell lysis. Nuclei were pelleted by centrifugation for $2 \mathrm{~min}$ at $10,000 \mathrm{rpm}$, and supernatant (cytoplasmic extract) fractions were collected. The nuclear pellet was resuspended in $50 \mu \mathrm{l}$ of buffer B (20 mM HEPES, pH 7.9, 0.4 M NaCl, 1 mM EDTA, $1 \mathrm{mM}$ DTT, $1 \mathrm{mM}$ PMSF, $1 \mathrm{mM}$ leupeptin), incubated for $30 \mathrm{~min}$ on ice, and centrifuged for $5 \mathrm{~min}$ at $10,000 \mathrm{rpm}$ at $4^{\circ} \mathrm{C}$ to obtain clear supernatant fractions (nuclear extract). $\mathrm{NF} \kappa \mathrm{B}$ consensus oligonucleotide ( $5^{\prime}$-AGT TGA GGG GAC TTT CCC AGG C- $\left.3^{\prime}\right), \mathrm{NF} \kappa \mathrm{B}$ mutant oligonucleotide (5'-AGT TGA GGC GAC TTT CCC AGG C-3'), and NF-IL6 (consensus) (nonspecific competitor - 5' -GGAGAGATTGCCTGACGTCAGAGAGGCA-3') (Santa Cruz Biotechnology) were labeled with digoxygenin (Dig) using a DIG Genius gel shift kit (Boehringer Mannheim, Indianapolis, IN, U.S.A.) and incubated overnight at $5^{\circ} \mathrm{C}$ with nuclear extract $(20 \mu \mathrm{g}$ of protein). The complexes were electrophoresed (0.5 Trisborate-EDTA buffer, $150 \mathrm{~V}$ for $2 \mathrm{hr}$ at room temperature) on Novex 6\% nondenaturing polyacrylamide gels (Invitrogen) and electroblotted ( $400 \mathrm{~mA}$ for $1 \mathrm{hr}$ ) in a sandwich procedure onto nitrocellulose (protein) and nylon (oligonucleotide) 
membranes. The Dig-labeled oligonucleotide was detected by anti-Dig alkaline phosphatase-conjugated Fab fragments and enhanced chemiluminescence. The p50 subunit of $\mathrm{NF} \kappa \mathrm{B}$ on the nitrocellulose membrane was probed by rabbit anti-NFkB (p50) antibody and detected by ECL Plus.

\subsection{N,N-diphenyl-N-picrylhydrzyl (DPPH) Radical Scaveng-} ing Activity. To evaluate the anti-oxidant activity of Rottlerin, the model of scavenging the stable free radical DPPH by hydrogen donating compounds was used.

As stock solutions, $20 \mu \mathrm{M}$ DPPH (A) and $10 \mu \mathrm{M}$ Rottlerin (B), were prepared in absolute ethanol and mixed by adding increasing volumes of the Rottlerin solution to that of DPPH in a final volume of $3 \mathrm{ml}$ to obtain DPPH/Rottlerin molar ratios $10: 1,4: 1$, and $2: 1$. The reaction mixtures were shaken vigorously and kept in the dark for $30 \mathrm{~min}$. The absorbance of the remaining DPPH was determined at $516 \mathrm{~nm}$ by UV/Vis Kontron 941 spectrophotometer.

For electron paramagnetic resonance (EPR) spectroscopy, the same DPPH/Rottlerin solutions were transferred to glass capillary tubes and then placed in the EPR cavity of a Varian E4 ESR spectrometer for spectral measurements.

2.6. ROS Measurement by FACS Analysis. Serum starved MCF-7 cells were pretreated with Rottlerin (5 and $20 \mu \mathrm{M}$ ) for $1 \mathrm{hr}$. The cells were loaded with $10 \mu \mathrm{M}$ DHR-123 for 15 minutes, washed by Hanks' Balanced Salt Solution (HBSS), and treated by the oxidative stress inducer, menadione $(100 \mu \mathrm{M})$, or $\mathrm{H}_{2} \mathrm{O}_{2}(100 \mu \mathrm{M})$ for $30 \mathrm{~min}$ in HBSS. The reaction was stopped by cooling on ice for $1 \mathrm{~min}$, and the cells were immediately analyzed by flow cytometry (BD FACSCalibur, excitation: $488 \mathrm{~nm}$ laser, emission: 530/30 nm). The level of ROS was indicated by median of DHR-123 fluorescence. Debris and dead cells were discriminated from the analysis using FSC versus SSC gating.

2.7. Luciferase Reporter Construct and Stable HT-29 Cell Transfection. The reporter construct pBIIX-LUC was kindly donated by Dr. Kalle Saksela (Institute of Molecular Medicine, University of Tampere, Finland). The NF- $\kappa$ Bdriven plasmid pBIIX-LUC was constructed by inserting a synthetic fragment with two copies of the sequence ACA GAG GGG ACT TTC CGA GAG separated by four nucleotides (ATCT) in front of the mouse fos promoter in plasmid pfLUC [18].

The reporter plasmid was cotransfected with pSV2neo neomycin-resistance plasmid into HT-29 (ATCC) cells using electroporation (Bio-Rad Laboratories, Inc.; Hercules, CA). Briefly, approximately $1 \times 10^{7}$ cells were mixed with $20 \mu \mathrm{g}$ of reporter plasmid and $2 \mu \mathrm{g}$ of pSV2neo plasmid, and electroporated $(275 \mathrm{~V}, 950 \mu \mathrm{F}, 2 \mathrm{x}$ pulse). Subsequently, the cells were seeded on a $100 \times 20 \mathrm{~mm}$ dish (TPP) with a feeder of HT-29 cells treated with mitomycin-C. Neomycinresistant clones were selected in $300 \mu \mathrm{g} / \mathrm{mL}$ of geneticin. The clones containing the reporter plasmid were confirmed by luciferase activity assay.
2.8. HT-29Cell Treatment and Luciferase Activity Assay. Stably transfected cells were seeded in 12-well plates and treated, $24 \mathrm{hr}$ later, with Rottlerin for $30 \mathrm{~min}$ followed by $\mathrm{TNF} \alpha(10 \mathrm{ng} / \mathrm{mL})$ for $4 \mathrm{hr}$. After the treatment, cells were rinsed with PBS and then lysed with $100 \mu \mathrm{l}$ of reagent (Luciferase Assay System; Promega Corp., Madison, WI). Fifty $\mu \mathrm{l}$ of the extracts was mixed with $50 \mu \mathrm{l}$ of luciferase substrate, and luminescence was quantified by luminometer.

2.9. Statistical Analysis. Results are reported as means \pm SEM. Statistical analysis was performed by using Student's $t$-test. $P<.05$ was considered statistically significant.

\section{Results}

3.1. Rottlerin Inhibits TNF $\alpha$-Induced NFאB Binding Activity in MCF-7 and HT-29 Cells. As shown in Figure 2, nuclear extracts from nonactivated MCF-7 and HT-29 cells (C) contained a basal or constitutive $\mathrm{NF} \kappa \mathrm{B} / \mathrm{DNA}$ binding activity which was not affected by $20 \mu \mathrm{M}$ Rottlerin treatment (R) nor by Vitamin E supplementation (V). Vitamin E was chosen as control since it is a well-known liposoluble antioxidant with the ability to inhibit NF $\kappa B$. Treatment with $10 \mathrm{ng} / \mathrm{ml}$ TNF $\alpha$ (T) caused an elevated level of NF $\kappa \mathrm{B} / \mathrm{DNA}$ binding and the pretreatment of cells with Rottlerin or Vitamin $\mathrm{E}(\mathrm{T}+\mathrm{R}$ and $\mathrm{T}+\mathrm{V}$ ) inhibited $\mathrm{TNF} \alpha$-induced $\mathrm{NF} \kappa \mathrm{B} / \mathrm{DNA}$ binding. The unlabeled $\mathrm{NF} \kappa \mathrm{B}$ consensus oligomer was used as the specific competitor and unlabeled NF-IL6 consensus oligomer as the nonspecific competitor.

3.2. Antioxidant Activity of Rottlerin: Reaction with DPPH. In the case of the UV measurements, the DPPH and Rottlerin spectra do not overlap and the complete disappearance of the typical absorption of DPPH at $514 \mathrm{~nm}$ was observed when equal volume of the DPPH and Rottlerin solutions, A and B, respectively, were mixed (Figure 3). Similar results were obtained by EPR, which directly measures the free radical concentration; by mixing the two solutions into the EPR cavity, the typical EPR signal of DPPH disappeared when equal volumes of the reagents solutions were mixed, that is in a $2: 1$ molar ratio (Figur 4), because two molecules of DPPH are reduced by one molecule of Rottlerin.

3.3. ROS Scavenging Activity of Rottlerin. As shown in Figure 5, both 5 and $20 \mu \mathrm{M}$ Rottlerin significantly decreases MCF-7 basal ROS levels and largely prevent ROS generated by a 30 -min treatment with either $100 \mu \mathrm{M} \mathrm{H}_{2} \mathrm{O}_{2}$ or $100 \mu \mathrm{M}$ menadione.

3.4. Effect of Rottlerin on NFאB Activation in HT-29 Transfected Cells. As shown in Figure 6, Rottlerin pretreatment for 30 min prevented activation of $\mathrm{NF} \kappa \mathrm{B}$ in a dose-dependent manner, both basal and after a $4 \mathrm{hr}$ TNF $\alpha$ treatment in HT-29 cells transfected with the NFKB-driven plasmid pBIIX-LUC.

These results confirm that Rottlerin is a general inhibitor of $\mathrm{NF} \kappa \mathrm{B}$ nuclear migration and transcriptional activity. 

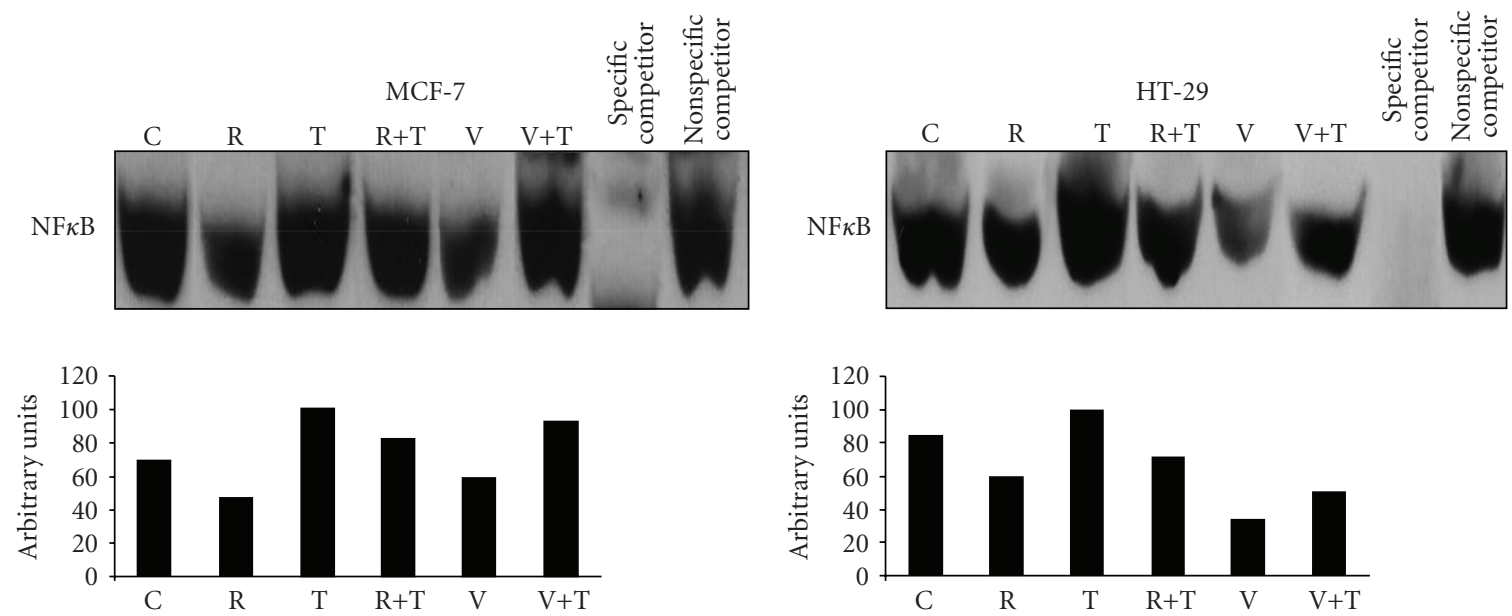

FIGURE 2: Rottlerin inhibits TNF $\alpha$-induced NF- $\kappa$ B/DNA binding activities in MCF-7 and HT-29 cells. Cells were pretreated with Rottlerin $(20 \mu \mathrm{M})$ or with Vitamin $\mathrm{E}(50 \mu \mathrm{M})$ with subsequent stimulation with $\mathrm{TNF} \alpha(10 \mathrm{ng} / \mathrm{mL})$ for 4 hr. Nuclear extracts $(20 \mu \mathrm{g})$ were used to determine NF-B DNA binding activities by electrophoretic mobility shift assay (EMSA) using DIG-labled oligonucleotide containing $\mathrm{NF} \kappa \mathrm{B}$ element. The unlabeled $\mathrm{NF} \kappa \mathrm{B}$ consensus oligomer was used as the specific competitor and unlabeled NF-L6 consensus oligomer as the nonspecific competitor. Bottom panel shows the bands quantification of a representative blot. Complexes were visualized by chemiluminescence. Lanes: C, control; R, Rottlerin; T, TNF $\alpha$; R+T; Rottlerin and TNF $\alpha$; V, Vitamin E; V+T, Vitamin E and TNF $\alpha$.

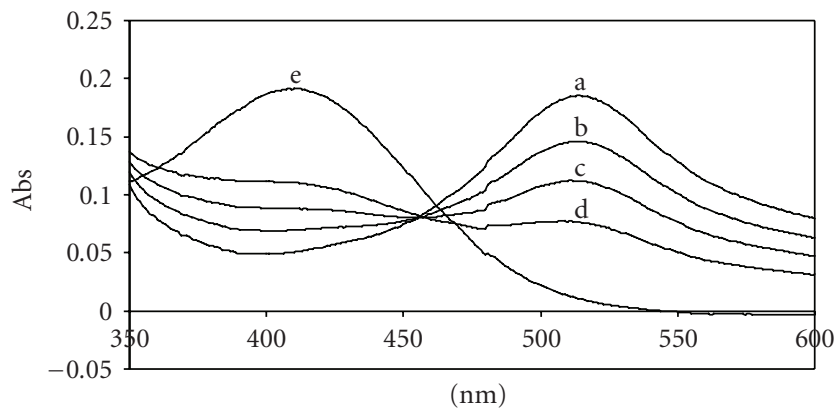

FIGURE 3: UV spectra of DPPH/Rottlerin solutions in absolute ethanol. (a) $20 \mu \mathrm{M}$ DPPH ethanol solution (A); (b) spectrum of the mixture DPPH/Rottlerin obtained by mixing $2.5 \mathrm{ml}$ of solution A with $0.5 \mathrm{ml}$ of solution $\mathrm{B}$ (10:1 molar ratio); (c) $2.0 \mathrm{ml}$ of solution A with $1 \mathrm{ml}$ of solution B (4:1 molar ratio); (d) $1.5 \mathrm{ml}$ of solution A with $1.5 \mathrm{ml}$ of solution B (2:1 molar ratio); (e) spectrum of $10 \mu \mathrm{M}$ Rottlerin ethanol solution (B).

\section{Discussion}

DPPH is a stable free radical, which is widely used to test the hydrogen donation of antioxidants [33]. Recently, the ability of Rottlerin to scavenge DPPH in comparison to other phenolic phytochemicals has been described. Empirically established concentrations of phytochemicals and DPPH showed that the Rottlerin scavenging ability was lower than that of resveratrol and genistein, higher than that of quercetin and epigallocatechin gallate, and roughly of the same order of that of curcumin [30].

In the present study, in order to further evaluate the hydrogen donation power of Rottlerin, we reacted one molecule of Rottlerin with two molecules of DPPH and

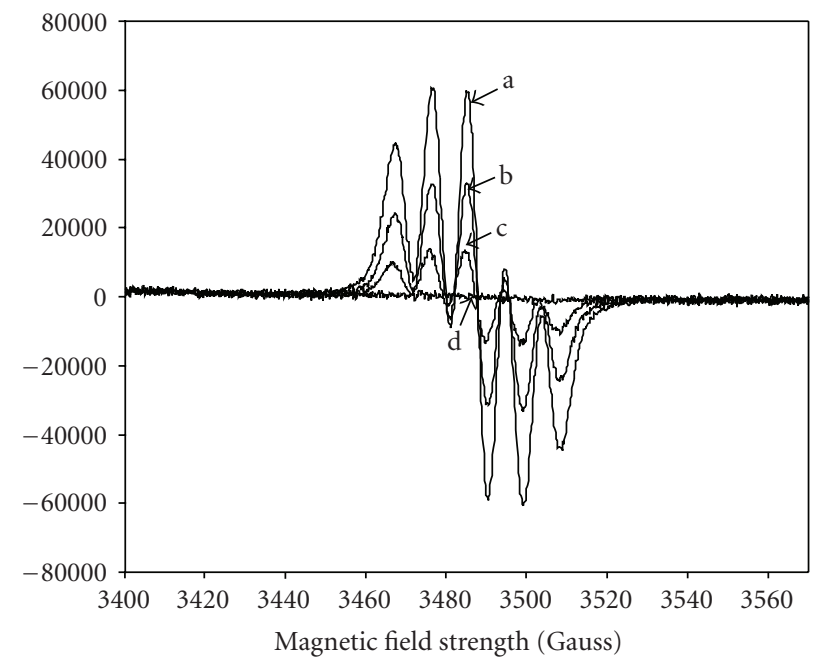

FIGURE 4: EPR spectra of DPPH /Rottlerin solutions in absolute ethanol. (a) $20 \mu \mathrm{M}$ DPPH ethanol solution (A); (b), (c), and (d) correspond to the (b), (c), and (d) solutions of Figure 2. All spectra were recorded in the same experimental conditions.

followed the reaction by UV measurement and EPR spectroscopy (Figures 2 and 3). This last reaction is thermodynamically supported by the fact that the Bond Dissociation Enthalpy of the N-H group of the reduced DPPH is $80 \mathrm{Kcal} / \mathrm{mol}$ [34] and that of the $\mathrm{O}-\mathrm{H}$ group of Vit-E is $77.9 \mathrm{Kcal} / \mathrm{mol}$ [35]. On the basis of this data it may be assumed that the hydrogen donation power of Rottlerin is of the same order of that of Vit-E, which is recognized like the best antioxidant for lipid systems [36].

The radical scavenging ability of polyphenols depends mainly on the positioning of the $\mathrm{O}-\mathrm{H}$ groups rather than on their number [37], and this could be evident in 


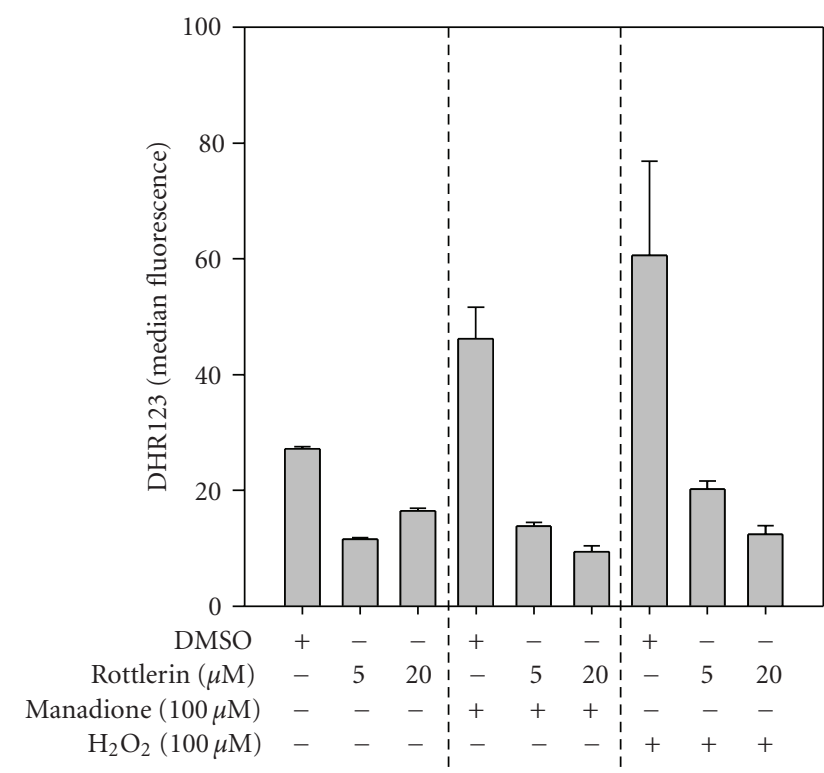

FIGURE 5: Rottlerin prevents both basal and induced intracellular production of $\mathrm{H}_{2} \mathrm{O}_{2}$. MCF-7 cells were pretreated with 5 and $20 \mu \mathrm{M}$ Rottlerin for $1 \mathrm{hr}$ and loaded by $\mathrm{H}_{2} \mathrm{O}_{2}$-specific fluorescent probe DHR-123. Cells were treated with menadione $(100 \mu \mathrm{M})$ and hydrogen peroxide $(100 \mu \mathrm{M})$ for $30 \mathrm{~min}$ and analyzed using flow cytometry.

Rottlerin, which possesses five phenolic $\mathrm{O}-\mathrm{H}$ all conjugated to the same $-\mathrm{CH}_{2}-$ group. This may suggest a higher antioxidant activity than that of the two frequently used ROS scavengers, namely, butylated hydroxyanisole (BHA) and butylatedhydroxytoluene (BHT), which show BDEs of 81.1 and $79.1 \mathrm{Kcal} / \mathrm{mol}$, respectively [38].

Because DPPH is an artificial radical and may not reproduce the in vivo situation, we also tested the Rottlerin antioxidant properties on cultured cells. According to the DPPH radical-reducing activity and its fast reactivity, Rottlerin neutralized hydrogen peroxide added to the cells and prevents free radicals generation (Figure 4). These finding are consistent with our previous report showing that Rottlerin quickly inhibited NF $\kappa$ B activation triggered by hydrogen peroxide in HaCaT keratinocytes [11] and are in accordance with the study by Longpre and Loo [30], showing that $20 \mu \mathrm{M}$ Rottlerin prevented deoxycholate-induced ROS generation in HCT-116 cells.

Rottlerin-mediated inhibition of $\mathrm{NF} \kappa \mathrm{B}$ is not restricted to PMA [10] and hydrogen peroxide [11] because it also blunts TNF $\alpha$-mediated NF $\kappa B$ activation. The current study indeed showed that $\mathrm{NF} \kappa \mathrm{B}$ nuclear migration and transcriptional activity, both basal and after stimulation by TNF $\alpha$, are strongly inhibited by the drug in native MCF-7 cells and in HT-29 cells, and in HT-29 transfected with the NF $\kappa$ Bdriven plasmid pBIIX-LUC, (2). Our results also parallel with a study by Zhang et al. where has been shown that Rottlerin inhibits NFאB activation in MCF7 sensitized cells to TRAILinduced apoptosis [39].

Taking in account the current results and previous data on PMA-stimulated MCF-7 cells [10] and $\mathrm{H}_{2} \mathrm{O}_{2}$-stimulatedHaCaT cells [11], it can be safely stated that Rottlerin is

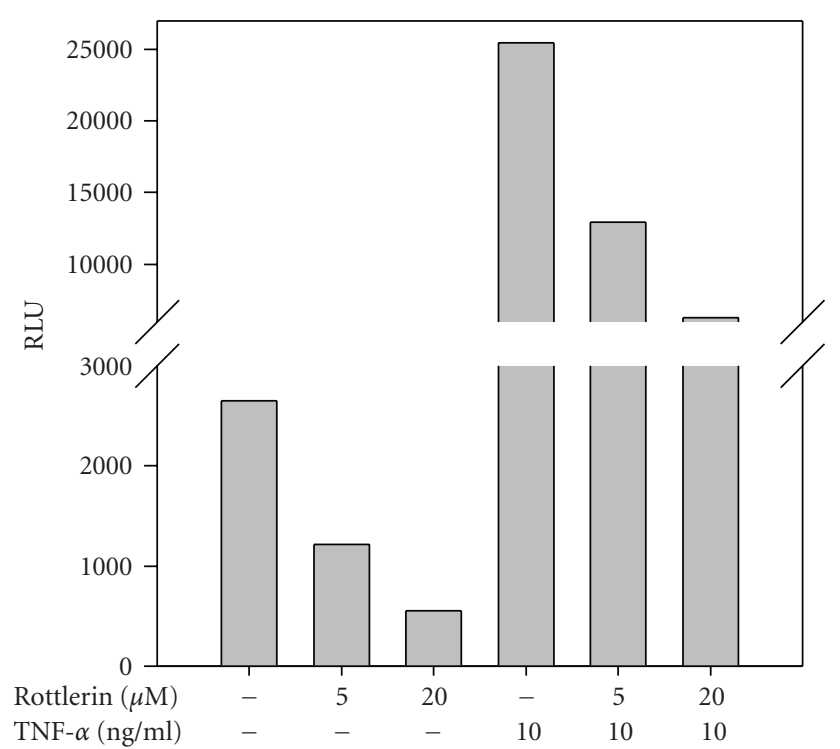

FIgURE 6: Effect of Rottlerin on NF $\kappa$ B nuclear translocation and transcriptional activity in HT-29 transfected cells. HT-29 cells, stably transfected with the NF $\kappa \mathrm{B}$-driven plasmid pBIIX-LUC, were pretreated for $30 \mathrm{~min}$ with 5 and $20 \mu \mathrm{M}$ Rottlerin and then treated with $10 \mathrm{ng} / \mathrm{mL}$ TNF $\alpha$ for $4 \mathrm{hr}$, before luciferase activity measurement. Data are the mean value \pm SD of four independent experiments.

a general inhibitor of $\mathrm{NF} \kappa \mathrm{B}$ regardless of the activation pathway (PMA, oxidative stress or TNF $\alpha$ ) and the cell type (MCF-7, HaCaT, HT-29 cells).

By integrating these findings, we conclude that the inhibitory effect of Rottlerin on $\mathrm{NF} \kappa \mathrm{B}$ is likely the result of a convergent double activity, free radical scavenging, and inhibition of key molecules, such as CaMKII [10] and/or PKC $[40,41]$ involved in the NF $\kappa$ B activation process.

Activation of $\mathrm{NF} \kappa \mathrm{B}$ is regulated by a bewildering number of signaling pathways, the contribution of which, in particular the cascade that mediates oxidative stress-induced $\mathrm{NF} \kappa \mathrm{B}$, is not always known in detail. The only target common to the several positive or negative signals to $\mathrm{NF} \kappa \mathrm{B}$ is the IKK complex, but this, representing the final converging step of the different cascades, does not give information on the upstream mediators.

It is likely that Rottlerin acts at a step in which all the stimuli used (PMA, $\mathrm{H}_{2} \mathrm{O}_{2}$, menadione, TNF $\alpha$ ) converge in the signal transduction pathway leading to $\mathrm{NF} \kappa \mathrm{B}$ activation.

It has been reported that $100 \mu \mathrm{M}$ Resveratrol blocks $\mathrm{NF} \kappa \mathrm{B}$ activation through inhibition of the upstream PKC $\delta / \mathrm{PKD}$ cascade in HeLa cells [41]. Since Rottlerin, at doses between 5 and $20 \mu \mathrm{M}$, is a PKC $\delta$ inhibitor, we initially thought that the Resveratrol's mechanism of action could explain also the Rottlerin effects on NF $\kappa$ B in MCF-7 cells. However, a preliminary experiment showed that $20 \mu \mathrm{M}$ Rottlerin did not inhibit PMA-stimulated PKD phosphorylation on Ser 744 and Ser 748 (unpublished observation), indicating that Resveratrol and Rottlerin, although both are antioxidant with similar potency [30] and PKC $\delta$ inhibitors, act with different mechanisms in NFKB inhibition. 
As far as the Rottlerin antioxidant effect is concerned, the interference of other natural antioxidants in the NF $\kappa \mathrm{B}$ activation process has been already described. For example, mangiferin, a natural polyphenol with antioxidant properties, and melatonin, another potent antioxidant, block TNFinduced $\mathrm{NF} \kappa \mathrm{B}$ activation $[42,43]$.

In closing, the antioxidant effect of Rottlerin surely plays a main role in the $\mathrm{NF} \kappa \mathrm{B}$ activation process triggered by PMA or $\mathrm{H}_{2} \mathrm{O}_{2}$ or menadione or TNF $\alpha$, but further studies will be necessary to establish the relative contribution of the two (chemical and biological) mechanisms and to clarify whether they act in parallel or in interdependent ways.

\section{Acknowledgments}

The authors thank Dr. K. Saksela for kindly providing the reporter construct pBIIX-LUC. This work was supported by project Grants from the Italian Ministero dell'Università e della Ricerca (MIUR) (programma rientro cervelli V.G.), research projects Grants from "Fondazione Monte dei Paschi Siena” (2008) and Grants no. 204/07/0834, no. 310/07/0961 of the Czech Science Foundation and by the Academy of Sciences of the Czech Republic, Grants no. AV0Z50040507 and AV0Z50040702.

\section{References}

[1] S. S. Gupta, P. Verma, and K. Hishikar, "Purgative and anthelmintic effects of Mallotus philippinensis in rats against tape worm," Indian Journal of Physiology and Pharmacology, vol. 28, no. 1, pp. 63-66, 1984.

[2] M. C. Srivastava, S. W. Singh, and J. P. Tewari, "Anthelmintic activity of Mallotus philippinensis-kambila powder," The Indian Journal of Medical Research, vol. 55, no. 7, pp. 746-748, 1967.

[3] M. S. Akhtar and I. Ahmad, "Comparative efficacy of Mallotus philippinensis fruit (Kamala) or Nilzan ${ }^{\circledR}$ drug against gastrointestinal cestodes in Beetal goats," Small Ruminant Research, vol. 8, no. 1-2, pp. 121-128, 1992.

[4] M. Gschwendt, H.-J. Muller, K. Kielbassa, et al., "Rottlerin, a novel protein kinase inhibitor," Biochemical and Biophysical Research Communications, vol. 199, no. 1, pp. 93-98, 1994.

[5] S. P. Soltoff, "Rottlerin: an inappropriate and ineffective inhibitor of PKC $\delta$," Trends in Pharmacological Sciences, vol. 28, no. 9, pp. 453-458, 2007.

[6] A. Daikonya, S. Katsuki, J.-B. Wu, and S. Kitanaka, "Antiallergic agents from natural sources (4): anti-allergic activity of new phloroglucinol derivatives from Mallotus philippensis (Euphorbiaceae)," Chemical and Pharmaceutical Bulletin, vol. 50, no. 12, pp. 1566-1569, 2002.

[7] R. Ishii, M. Horie, K. Saito, M. Arisawa, and S. Kitanaka, "Inhibition of lipopolysaccharide-induced pro-inflammatory cytokine expression via suppression of nuclear factor- $\kappa \mathrm{B}$ activation by Mallotus japonicus phloroglucinol derivatives," Biochimica et Biophysica Acta, vol. 1620, no. 1-3, pp. 108-118, 2003.

[8] S. P. Soltoff, "Rottlerin is a mitochondrial uncoupler that decreases cellular ATP levels and indirectly blocks protein kinase C $\delta$ tyrosine phosphorylation," Journal of Biological Chemistry, vol. 276, no. 41, pp. 37986-37992, 2001.
[9] S. I. Zakharov, J. P. Morrow, G. Liu, L. Yang, and S. O. Marx, "Activation of the BK (SLO1) potassium channel by mallotoxin," Journal of Biological Chemistry, vol. 280, no. 35, pp. 30882-30887, 2005.

[10] C. Torricelli, V. Fortino, E. Capurro, et al., "Rottlerin inhibits the nuclear factor $\kappa \mathrm{B} /$ cyclin-D1 cascade in MCF-7 breast cancer cells," Life Sciences, vol. 82, no. 11-12, pp. 638-643, 2008.

[11] G. Valacchi, A. Pecorelli, M. Mencarelli, et al., "Rottlerin: a multifaced regulator of keratinocyte cell cycle," Experimental Dermatology, vol. 18, no. 6, pp. 516-521, 2009.

[12] S. P. Davies, H. Reddy, M. Caivano, and P. Cohen, "Specificity and mechanism of action of some commonly used protein kinase inhibitors," Biochemical Journal, vol. 351, no. 1, pp. 95$105,2000$.

[13] S. I. Cho, M. Koketsu, H. Ishihara, et al., "Novel compounds, '1,3-selenazine derivatives' as specific inhibitors of eukaryotic elongation factor-2 kinase," Biochimica et Biophysica Acta, vol. 1475, no. 3, pp. 207-215, 2000.

[14] O. N. Ozes, L. D. Mayo, J. A. Gustin, S. R. Pfeffer, L. M. Pfeffer, and D. B. Donner, "NF- $\kappa$ B activation by tumour necrosis factor requires tie Akt serine-threonine kinase," Nature, vol. 401, no. 6748, pp. 82-85, 1999.

[15] W. Ouyang, J. Li, Q. Ma, and C. Huang, "Essential roles of $\mathrm{PI}-3 \mathrm{~K} / \mathrm{Akt} / \mathrm{IKK} \beta / \mathrm{NF} \kappa \mathrm{B}$ pathway in cyclin D1 induction by arsenite in JB6 Cl41 cells," Carcinogenesis, vol. 27, no. 4, pp. 864-873, 2006.

[16] K. Hughes, S. Edin, A. Antonsson, and T. Grundström, "Calmodulin-dependent kinase II mediates T cell receptor/ CD3-and phorbol ester-induced activation of I $\kappa \mathrm{B}$ kinase," Journal of Biological Chemistry, vol. 276, no. 38, pp. 3600836013, 2001.

[17] J. Choi, L. A. Krushel, and K. L. Crossin, "NF- $\kappa$ B activation by $\mathrm{N}$-CAM and cytokines in astrocytes is regulated by multiple protein kinases and redox modulation," Glia, vol. 33, no. 1, pp. 45-56, 2001.

[18] C. J. Howe, M. M. Lahair, J. A. Maxwell, et al., "Participation of the calcium/calmodulin-dependent kinases in hydrogen peroxide-induced $\mathrm{I} \kappa \mathrm{B}$ phosphorylation in human T lymphocytes," Journal of Biological Chemistry, vol. 277, no. 34, pp. 30469-30476, 2002.

[19] S. Mishra, J. P. Mishra, K. Gee, D. C. McManus, E. C. LaCasse, and A. Kumar, "Distinct role of calmodulin and calmodulindependent protein kinase-II in lipopolysaccharide and tumor necrosis factor- $\alpha$-mediated suppression of apoptosis and antiapoptotic c-IAP2 gene expression in human monocytic cells," Journal of Biological Chemistry, vol. 280, no. 45, pp. 37536-37546, 2005.

[20] T. Banno, A. Gazel, and M. Blumenberg, "Pathway-specific profiling identifies the NF- $\kappa \mathrm{B}$-dependent tumor necrosis factor $\alpha$-regulated genes in epidermal keratinocytes," Journal of Biological Chemistry, vol. 280, no. 19, pp. 18973-18980, 2005.

[21] P. Viatour, M.-P. Merville, V. Bours, and A. Chariot, "Phosphorylation of NF- $\kappa$ B and $\mathrm{I} \kappa \mathrm{B}$ proteins: implications in cancer and inflammation," Trends in Biochemical Sciences, vol. 30, no. 1, pp. 43-52, 2005.

[22] S. Schoonbroodt and J. Piette, "Oxidative stress interference with the nuclear factor- $\kappa \mathrm{B}$ activation pathways," Biochemical Pharmacology, vol. 60, no. 8, pp. 1075-1083, 2000.

[23] H. Jayasuriya, J. D. Mcchesney, S. M. Swanson, and J. M. Pezzuto, "Antimicrobial and cytotoxic activity of rottlerintype compounds from Hypericum drummondii," Journal of Natural Products, vol. 52, no. 2, pp. 325-331, 1989. 
[24] H. Sakagami, Y. Jiang, K. Kusama, et al., "Induction of apoptosis by flavones, flavonols (3-hydroxyflavones) and isoprenoid-substituted flavonoids in human oral tumor cell lines," Anticancer Research, vol. 20, no. 1A, pp. 271-277, 2000.

[25] K. Subbaramaiah, W. J. Chung, P. Michaluart, et al., "Resveratrol inhibits cyclooxygenase-2 transcription and activity in phorbol ester-treated human mammary epithelial cells," Journal of Biological Chemistry, vol. 273, no. 34, pp. 2187521882, 1998.

[26] Y. Li, F. Ahmed, S. Air, P. A. Philip, O. Kucuk, and F. H. Sarkar, "Inactivation of nuclear factor $\kappa \mathrm{B}$ by soy isoflavone genistein contributes to increased apoptosis induced by chemotherapeutic agents in human cancer cells," Cancer Research, vol. 65, no. 15, pp. 6934-6942, 2005.

[27] Y. Li, F. Ahmed, S. Air, P. A. Philip, O. Kucuk, and F. H. Sarkar, "Erratum: inactivation of nuclear factor $\kappa \mathrm{B}$ by soy isoflavone genistein contributes to increased apoptosis induced by chemotherapeutic agents in human cancer cells," Cancer Research, vol. 65, no. 23, p. 11228, 2005.

[28] N. Ahmad, S. Gupta, and H. Mukhtar, "Green tea polyphenol epigallocatechin-3-gallate differentially modulates nuclear factor $\kappa \mathrm{B}$ in cancer cells versus normal cells," Archives of Biochemistry and Biophysics, vol. 376, no. 2, pp. 338-346, 2000.

[29] K. M. Dhandapani, V. B. Mahesh, and D. W. Brann, "Curcumin suppresses growth and chemoresistance of human glioblastoma cells via AP-1 and NF $\kappa$ B transcription factors," Journal of Neurochemistry, vol. 102, no. 2, pp. 522-538, 2007.

[30] J. M. Longpre and G. Loo, "Protection of human colon epithelial cells against deoxycholate by rottlerin," Apoptosis, vol. 13, no. 9, pp. 1162-1171, 2008.

[31] G. Valacchi, E. Pagnin, A. Phung, et al., "Inhibition of NF $\kappa B$ activation and IL-8 expression in human bronchial epithelial cells by acrolein," Antioxidants and Redox Signaling, vol. 7, no. 1-2, pp. 25-31, 2005.

[32] P. Molyneux, "The use of stable free radical diphenylpicrylhydrazyl (DPPH) for estimating antioxidant activity," Songklanakarin Journal of Science \& Technology, vol. 26, no. 2, pp. 211-219, 2004.

[33] K. Saksela and D. Baltimore, "Negative regulation of immunoglobulin kappa light-chain gene transcription by a short sequence homologous to the murine $\mathrm{B} 1$ repetitive element," Molecular and Cellular Biology, vol. 13, no. 6, pp. 3698-3705, 1993.

[34] Y.-R. Luo, Handbook of Dissociation Energies in Organic Compounds, CRC, Boca Raton, Fla, USA, 2003.

[35] R.-M. Borges dos Santos and J.-A. Martinho Simoes, "Energetic of the $\mathrm{OH}$ bond in phenol and substituted phenols: a critical evaluation data," Journal of Physical and Chemical Reference Data, vol. 27, no. 3, pp. 707-739, 1998.

[36] V. W. Bowry and K. U. Ingold, "The unexpected role of vitamin $\mathrm{E}$ ( $\alpha$-tocopherol) in the peroxidation of human lowdensity lipoprotein," Accounts of Chemical Research, vol. 32, no. 1, pp. 27-34, 1999.

[37] V. Thavasi, L. P. Leong, and R. P. A. Bettens, "Investigation of the influence of hydroxy groups on the radical scavenging ability of polyphenols," Journal of Physical Chemistry A, vol. 110, no. 14, pp. 4918-4923, 2006.

[38] E. Denisov, Handbook of Antioxidants: Bond Dissociation Energies, Rate Constants, Activation Energies and Enthalpies of Reactions, CRC, Boca Raton, Fla, USA, 1995.

[39] J. Zhang, N. Liu, J. Zhang, S. Liu, Y. Liu, and D. Zheng, "PKC $\delta$ protects human breast tumor MCF-7 cells against tumor necrosis factor-related apoptosis-inducing ligand-mediated apoptosis," Journal of Cellular Biochemistry, vol. 96, no. 3, pp. 522-532, 2005.

[40] E. Kontny, M. Kurowska, K. Szczepanska, and W. Maslinski, "Rottlerin, a PKC isozyme-selective inhibitor, affects signaling events and cytokine production in human monocytes," Journal of Leukocyte Biology, vol. 67, no. 2, pp. 249-258, 2000.

[41] P. Storz, H. Döppler, and A. Toker, "Activation loop phosphorylation controls protein kinase D-dependent activation of nuclear factor $\kappa \mathrm{B}$," Molecular Pharmacology, vol. 66, no. 4, pp. 870-879, 2004.

[42] A. Sarkar, Y. Sreenivasan, G. T. Ramesh, and S. K. Manna, " $\beta$-D-glucoside suppresses tumor necrosis factor-induced activation of nuclear transcription factor $\kappa \mathrm{B}$ but potentiates apoptosis," Journal of Biological Chemistry, vol. 279, no. 32, pp. 33768-33781, 2004.

[43] M. Sasaki, P. Jordan, T. Joh, et al., "Melatonin reduces TNF-a induced expression of MAdCAM-1 via inhibition of NF- $\kappa \mathrm{B}$," BMC Gastroenterology, vol. 2, article 9, 2002. 

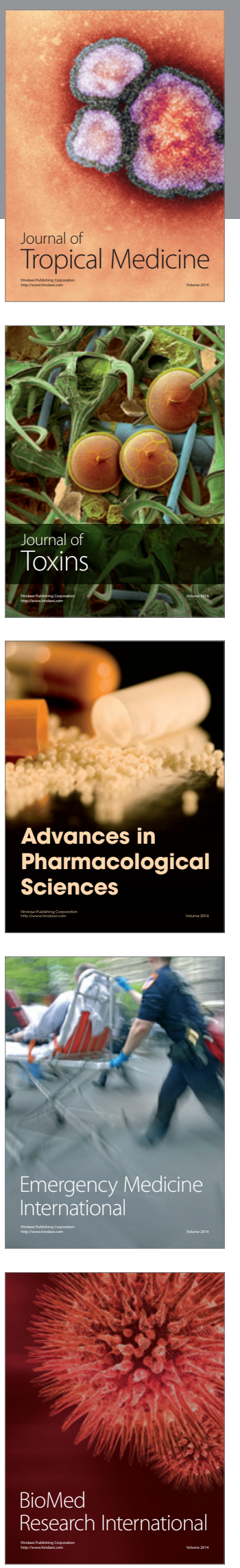
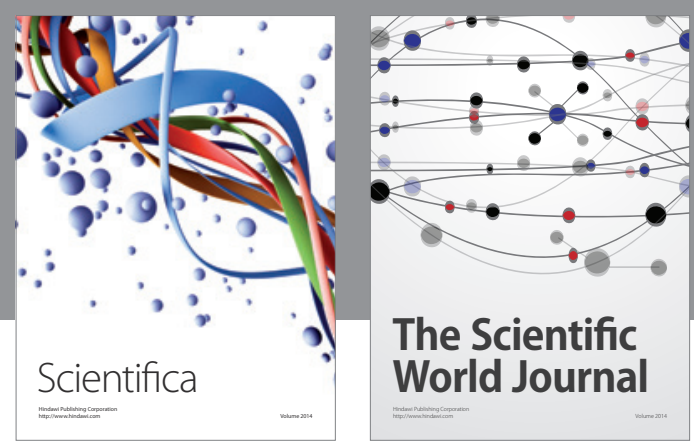

The Scientific World Journal
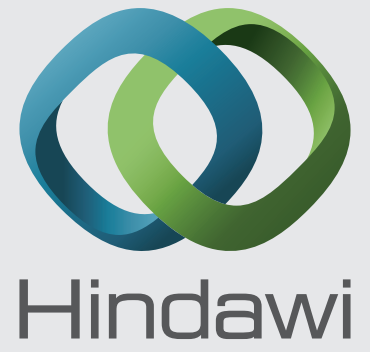

Submit your manuscripts at

http://www.hindawi.com
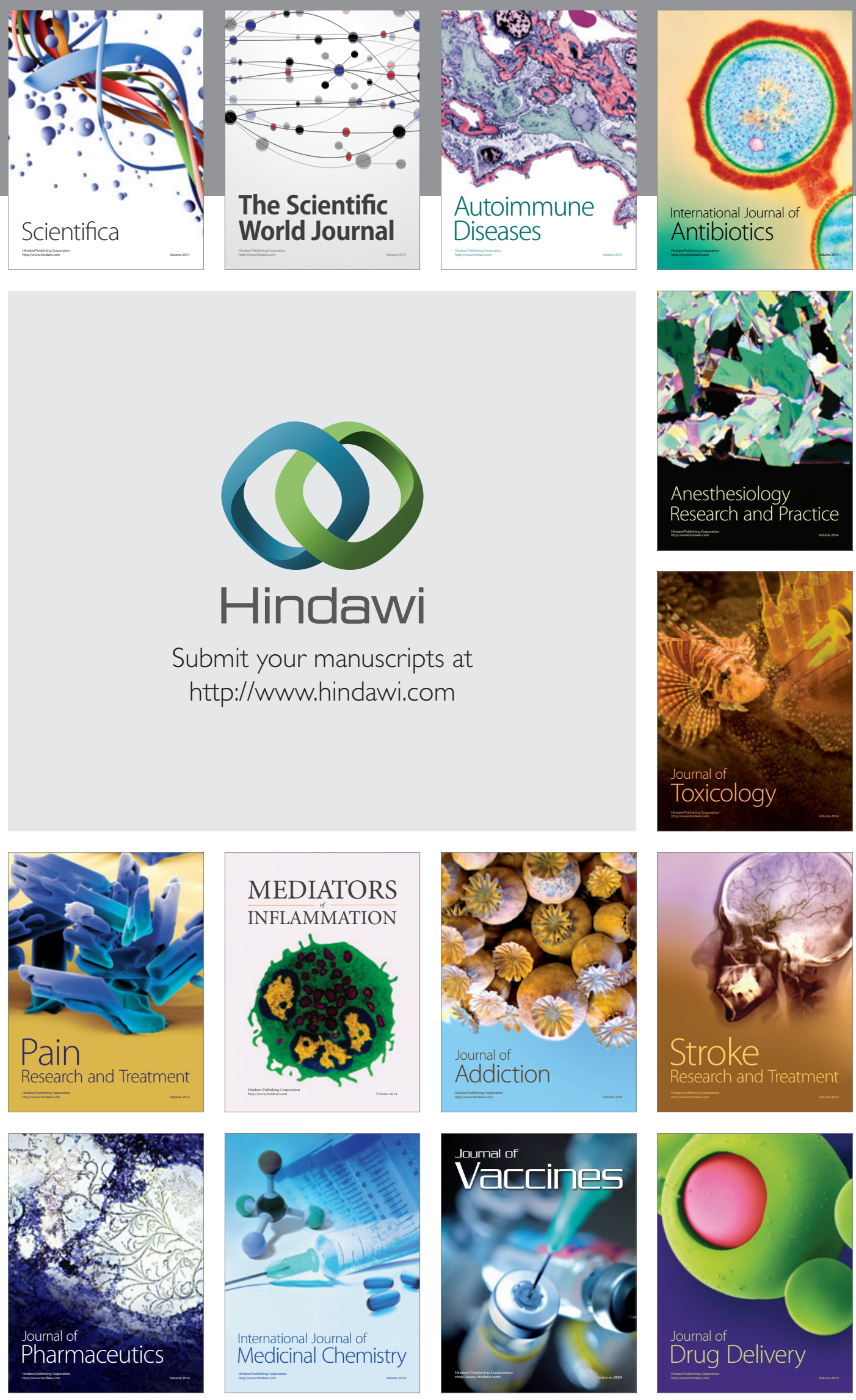